\title{
Homogeneous oxidation of alcohol and alkene with copper (II) complex in water
}

\author{
HAKAN ÜNVER*(D and IBRAHIM KANI \\ Department of Chemistry, Faculty of Science, Anadolu University, 26210 Eskisehir, Turkey \\ E-mail: hakanunver@anadolu.edu.tr
}

MS received 16 January 2018; revised 14 February 2018; accepted 20 February 2018; published online 19 March 2018

\begin{abstract}
A new water-soluble copper(II) complex bearing 4-bromobenzoate/2,2'-dipyridylamine ligands was successfully synthesized and characterized by using single crystal X-ray diffraction and spectroscopic techniques. The catalytic activity of the compound was investigated as a homogeneous catalyst in the oxidation of several alcohols (benzyl alcohol, cinnamyl alcohol, 1-phenylethanol, cyclohexanol, 1-heptanol) and alkenes (styrene, ethylbenzene, cyclohexene) in aqueous medium. The copper(II) catalyst was found to be active for the studied alcohols and alkenes. $\mathrm{H}_{2} \mathrm{O}_{2}$ was used as an active oxidant for alcohol oxidation, while $t$ - $\mathrm{BuOOH}$ (TBHP) was used for alkenes. The compound exhibited high selectivity toward benzaldehyde ( $88 \%$ ) in cinnamyl alcohol oxidation under mild conditions $\left(70{ }^{\circ} \mathrm{C}\right)$ after $4 \mathrm{~h}$. Particularly, remarkable results were obtained for the oxidation of styrene and cyclohexene; transformation via allylic oxidation to 2-cyclohexene-1-one as one product in $2 \mathrm{~h}\left(\mathrm{TOF}=50 \mathrm{~h}^{-1}\right)$ and benzaldehyde in $1 \mathrm{~h}\left(100 \%\right.$ conversion, TOF $=86 \mathrm{~h}^{-1}, 100 \%$ selectivity $)$. The $\mathrm{Cu}(\mathrm{II}) / \mathrm{TBHP}$ (or $\mathrm{H}_{2} \mathrm{O}_{2}$ ) $/ \mathrm{H}_{2} \mathrm{O}$ system proved to be an alternative for catalytic oxidations in the green chemistry concept.
\end{abstract}

Keywords. Copper (II) complex; oxidation; alcohol; alkene.

\section{Introduction}

Chemical reaction in green solvent systems is one of the major investigation areas of green synthesis. The number of published environmentally friendly catalytic systems in the literature is increasing over time. There are many examples of catalytic reactions performed in supercritical fluids, ${ }^{1}$ ionic liquids,${ }^{2}$ fluorous solvents, ${ }^{3}$ or solvent-free systems. ${ }^{4,5}$ Reactions especially applied in water solvent systems are extremely important because they have many advantages, such as non-toxicity, absence of hazards, low wastage in production, economical method, and so on. Water has been used as a solvent in many types of transition metalcatalyzed reactions, i.e., carbonylation, ${ }^{6}$ arylation, ${ }^{7}$ hydroformylation, ${ }^{8}$ and hydrogenation. ${ }^{9}$ In synthetic chemical production processes, such as those in the dye, pigment, medicine, and perfume industries, selective alcohol and alkene oxidations are important reactions for obtaining numerous starting or intermediate chemicals, aldehydes, ketones, diols, and carboxylic acids.

\footnotetext{
*For correspondence
}

Expensive transition metal catalysts, i.e., as palladium, ${ }^{10}$ platinum, ${ }^{11}$ and ruthenium ${ }^{12}$ have been reported to be efficient catalysts for alcohol and alkene oxidations in water. Compared to the aforementioned high-cost metal compounds, relatively low-cost metal catalysts, such as copper, ${ }^{13}$ iron, ${ }^{14}$ and manganese ${ }^{15}$ compounds are a lot scarce for homogeneous catalytic oxidations in water. In this respect, the catalytic oxidation of alcohol and alkenes in water to the corresponding products has always attracted interest in the past decade. ${ }^{13,16-22}$

Many copper complexes have been found to catalyze for peroxidative oxidation in homogeneous and heterogeneous catalytic systems. ${ }^{23-27}$ Some Cu-Schiff base complexes in a heterogeneous system can lead to a higher yield $\left(\sim 90 \%\right.$, TOF $\left.=18.2 \mathrm{~h}^{-1}\right)$ of products in cyclohexene oxidation. ${ }^{28}$ Mizar et al., published a study of an effective catalyst for benzyl alcohol for benzaldehyde transformation with copper(II)-2-Narylpyrrolecarbaldimine catalysts under atmospheric oxygen pressure at $80^{\circ} \mathrm{C}$ within $2 \mathrm{~h}$ in water (yield : 68$99 \%) .{ }^{29} \mathrm{Hu}$ et al., synthesized and used some copper complexes with tetradentate pyridyl-imine terminated

Electronic supplementary material: The online version of this article (https://doi.org/10.1007/s12039-018-1439-y) contains supplementary material, which is available to authorized users. 
Schiff base ligands to investigate their aerobic alcohol oxidation activities in aqueous media. ${ }^{30}$

To the best of our knowledge, water-soluble carboxylate- $\mathrm{Cu}$ (II)-catalyzed reactions of alkenes to ketones and also the oxidation of alcohols in water are very scarce. Recently, we published a successful application of a new copper(II)/triphenylacetic acid/bipyridyl complex for oxidation of primary and secondary alcohols with $\mathrm{H}_{2} \mathrm{O}_{2}$ under mild conditions in pure water. ${ }^{31}$ Water-soluble copper(II) complexes with sulfonicfunctionalized arylhydrazone of $\beta$-diketone are used as catalyst precursors for the selective peroxidative (with TBHP) allylic oxidation of cyclohexene to cyclohex2-enol (Cy-ol) and cyclohex-2-enone (Cy-one) with a total yield of $\sim 70 \%$ and TONs of up to $350,{ }^{29}$ but that is lower than those $(>90 \%)$ we observed in our $\mathrm{Cu}$ (II)-complex. Copper(II) catalytic systems with mixed-ligand aminoalcohol-dicarboxylate coordination polymers act as homogeneous catalysts in aqueous acetonitrile under mild conditions (50-60 ${ }^{\circ} \mathrm{C}$ ): the oxidation of cyclohexene through $\mathrm{H}_{2} \mathrm{O}_{2}$ and in the presence of a trifluoroacetic acid promoter results in total product yields $(\sim 15-18 \%$ based on the substrate). ${ }^{32-36} \mathrm{Cu}-\mathrm{MOF}$, $\left[\mathrm{Cu}(\right.$ bpy $)\left(\mathrm{H}_{2} \mathrm{O}\right)_{2}\left(\mathrm{BF}_{4}\right)_{2}$ (bpy)] (bpy: 4,4'-bipyridine), exhibited catalytic activity and high selectivity in the allylic oxidation of cyclohexene with molecular oxygen under solvent-free conditions (TON $=13-37) .{ }^{25}$ However, these catalysts show lower selectivity than our systems. Therefore, the title $\mathrm{Cu}$ (II)complex is the best catalyst precursor for selective allylic cyclohexene oxidation, which results in the formation of ketone as a single product.

Herein, we present a new water-soluble copper(II)/ 4-bromobenzoate/2,2'-dipyridylamine complex ([Cu $\left.\left.\left(\mathrm{OOC}\left(\mathrm{C}_{6} \mathrm{H}_{5}\right) \mathrm{Br}\right)\left(\mathrm{C}_{10} \mathrm{H}_{9} \mathrm{~N}_{3}\right)\right]\left(\mathrm{ClO}_{4}\right)\right)$ and its successful application for selective oxidation of alcohols and alkenes under mild reaction medium $\left(70^{\circ} \mathrm{C}\right)$ with $\mathrm{H}_{2} \mathrm{O}_{2}$ or $t$ - $\mathrm{BuOOH}$ in green solvent water.

\section{Experimental}

\subsection{Materials and Physical measurements}

All chemicals were obtained from commercial companies ( $\geq$ 98\%, Sigma-Aldrich and Merck, Germany) and used without further purification. IR spectra were recorded with Jasco FT/IR-300 E Spectrophotometer using $\mathrm{KBr}$ pellets between 4000 and $400 \mathrm{~cm}^{-1}$. UV spectra were recorded using a Shimadzu UV-2450 spectrophotometer. Crystallographic data were collected with Bruker APEX II CCD using Mo-Ka radiation at room temperature and corrected for absorption with SADABS. A complex structure solution was performed using direct methods. Non-hydrogen atoms were refined anisotropically using full-matrix least squares on F2.

\subsection{Synthesis of complex, $\left(\left[\mathrm{Cu}\left(\mathrm{OOC}\left(\mathrm{C}_{6} \mathrm{H}_{5}\right) \mathrm{Br}\right)\right.\right.$ \\ $\left.\left.\left(\mathrm{C}_{10} \mathrm{H}_{9} \mathrm{~N}_{3}\right)\right]\left(\mathrm{ClO}_{4}\right)\right)$, ([aqua(4-bromobenzoato) \\ (2,2'dipyridylamine) copper(II)](perchlorate))}

Neutralized solution of 4-bromobenzoic acid (100 mg, 0.49 mmol, $10 \mathrm{~mL}$ methanol) with sodium hydroxide $(19.5 \mathrm{mg}$, $0.49 \mathrm{mmol}$ ) was added dropwise to the methanolic solution of copper(II) perchlorate hexahydrate $(10 \mathrm{~mL}, 181 \mathrm{mg}, 0.49$ $\mathrm{mmol}$ ) at $50{ }^{\circ} \mathrm{C}$ for $2 \mathrm{~h}$. Then, 2,2'-dipyridylamine solution in methanol ( $84 \mathrm{mg}, 0.49 \mathrm{mmol}, 5 \mathrm{~mL}$ ) was reacted overnight with a metal salt-bromobenzoate solution to obtain a copper(II) complex. Dark-blue crystals were obtained from the evaporation of the solvent after 7 days $(180 \mathrm{mg}$, yield 69\%, M.p.: $\left.250^{\circ} \mathrm{C}\right)$ FT-IR $\left(\mathrm{KBr} ; \nu, \mathrm{cm}^{-1}\right)$ (s. strong; m. medium; w. weak): $3416 \mathrm{w} v_{\mathrm{N}-\mathrm{H}} ; 1590 \mathrm{~m} \nu_{\mathrm{C}=\mathrm{N}} ; 1644 \mathrm{~m} \nu_{\text {COOasym }} ; 1484 \mathrm{~m}$ $\nu_{\text {COOsym }} ; 1530 \mathrm{~m} v_{\mathrm{C}=\mathrm{N}-\mathrm{C}=\mathrm{C}} ; 1114 \mathrm{~m} \nu_{\mathrm{O}-\mathrm{H}} ; 1088 \mathrm{~s} \nu_{\mathrm{C}-\mathrm{O}}$; $769 \mathrm{~m} \nu_{\mathrm{C}-\mathrm{N}} ; 625 \mathrm{~m} \nu_{\mathrm{Cu}-\mathrm{O}-\mathrm{Cu}} \mathrm{UV}-\mathrm{Vis} \lambda_{\max } \mathrm{nm}\left(\mathrm{CH}_{3} \mathrm{CN}\right)$ : 244. 295. 312. Magnetic moment $(\mu)=1.4$ B.M. at room temperature.

\section{$2.3 X$-ray crystallography}

Diffraction data for the complex collected with Bruker AXS APEX CCD diffractometer equipped with a rotation anode at 296 (2) K, respectively using graphite monochromated Mo $\mathrm{K} \alpha$ radiation at $\lambda=0.71073 \AA$. The data reduction was performed with the Bruker SMART program package. ${ }^{37}$ The structures were solved by direct methods and the nonhydrogen atoms were located through subsequent difference Fourier syntheses. ${ }^{38}$ Structure solution was found with the SHELXS-97 package using the direct methods and were refined SHELXL-97 ${ }^{39}$ against $\mathrm{F}^{2}$ using first isotropic and later anisotropic thermal parameters for all non-hydrogen atoms. Hydrogen atoms were added to the structure model at calculated positions. The molecular drawing was obtained using MERCURY. ${ }^{40}$ Geometric calculations were performed with PLATON. ${ }^{41}$

\subsection{General procedure for alcohol/alkene oxidation}

Alcohol or alkene $\left(9.3 \times 10^{-4} \mathrm{~mol}\right)$ (substrate/catalyst ratio $=100)$ copper catalyst $\left(9.3 \times 10^{-6} \mathrm{~mol}\right)$ and oxidant $\mathrm{H}_{2} \mathrm{O}_{2}(2$ $\left.\mathrm{mL}, 1.92 \times 10^{-4} \mathrm{~mol}\right)$ or $t-\mathrm{BuOOH}\left(2 \mathrm{~mL}, 1.4 \times 10^{-2} \mathrm{~mol}\right)$ were mixed in $10 \mathrm{~mL}$ water in a $50 \mathrm{~mL}$ reaction flask with a condenser at $70^{\circ} \mathrm{C}$ for $24 \mathrm{~h}$. Internal samples were taken from reaction media after certain time intervals for monitoring the substrate/product(s) percentage on a GC with an HP-5 quartz capillary column $(30 \mathrm{~m} \times 0.32 \mathrm{~mm} \times 0.25 \mu \mathrm{m})$ and a flame ionization detector (FID). An unknown peak definition was made by analyzing real GC standards. 


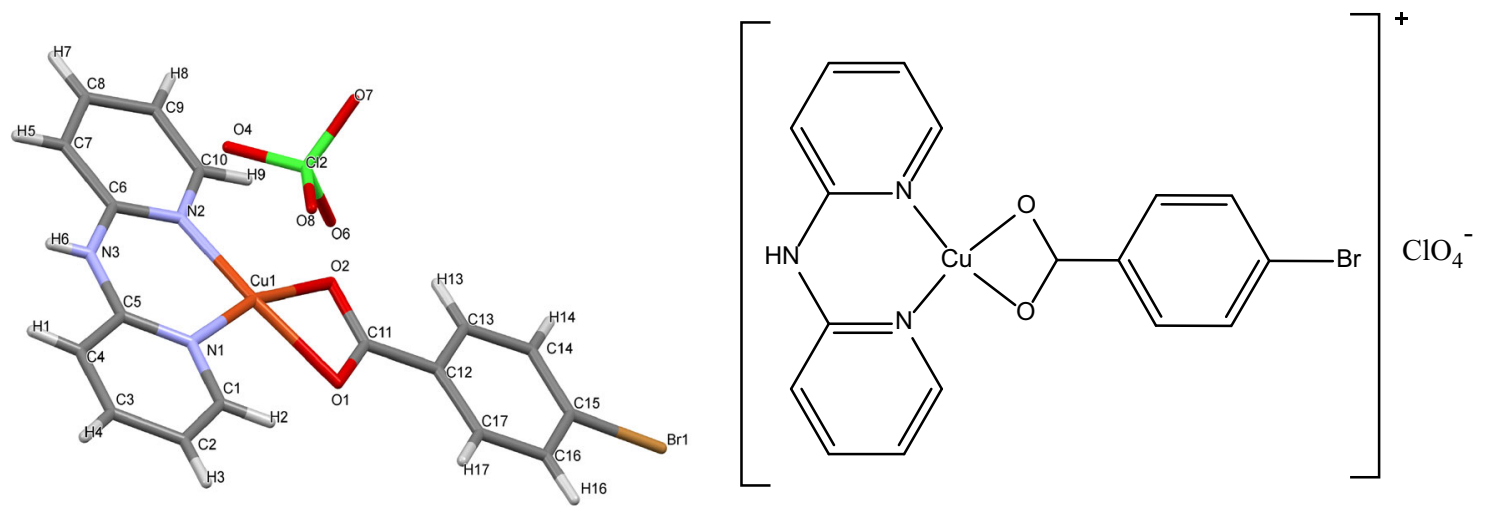

Figure 1. Molecular and ChemDraw structures of the complex 1.

Table 1. Crystal data and structure refinement for complex 1.

\begin{tabular}{ll}
\hline Empirical formula & $\mathrm{C}_{17} \mathrm{H}_{13} \mathrm{BrClCuN}_{3} \mathrm{O}_{6}$ \\
Formula weight & 534.20 \\
Temperature & $296(2) \mathrm{K}$ \\
Wavelength & $0.71073 \AA$ \\
Crystal system, space group & monoclinic, $\mathrm{P} 21 / \mathrm{c}$ \\
Unit cell dimensions & $\mathrm{a}=7.018(3) \AA$ alpha $=90^{\circ}$ \\
& $\mathrm{b}=20.472(8) \AA$ beta $=99.25(3)$ degr \\
& $\mathrm{c}=13.619(6) \AA$ gamma $=90^{\circ}$ \\
Volume & $1931.3(13) \mathrm{A}^{3}$ \\
Z, Calculated density & $4,1.837 \mathrm{Mg} / \mathrm{m}^{3}$ \\
Absorption coefficient & $3.379 \mathrm{~mm}^{-1}$ \\
F(000) & 1060 \\
Crystal size & $0.22 \times 0.18 \times 0.09 \mathrm{~mm}$ \\
Theta range for data collection & 1.81 to 28.97 degr \\
Limiting indices & $-9<=\mathrm{h}<=9,-27<=\mathrm{k}<=24,-14<=1<=18$ \\
Reflections collected/unique & $16900 / 4864[\mathrm{R}(\mathrm{int})=0.0670]$ \\
Completeness to theta $=28.97$ & $94.7 \%$ \\
Absorption correction & Integration \\
Max. and min. transmission & 0.7507 and 0.5235 \\
Refinement method & Full-matrix least-squares on $\mathrm{F}^{2}$ \\
Data/restraints/parameters & $4864 / 0 / 274$ \\
Goodness-of-fit on $\mathrm{F}^{2}$ & 0.951 \\
Final R indices [I 2 2sigma(I)] & $\mathrm{R} 1=0.0570, \mathrm{wR} 2=0.1491$ \\
R indices (all data) & $\mathrm{R} 1=0.1076, \mathrm{wR} 2=0.1777$ \\
Largest diff. peak and hole & 0.580 and $-1.052 \mathrm{e} . \mathrm{A}^{-3}$ \\
&
\end{tabular}

\section{Results and Discussion}

\subsection{Structural analysis of the complex 1}

The copper(II)-complex, $\left(\left[\mathrm{Cu}\left(\mathrm{OOC}\left(\mathrm{C}_{6} \mathrm{H}_{5}\right) \mathrm{Br}\right)\left(\mathrm{C}_{10} \mathrm{H}_{9}\right.\right.\right.$ $\left.\left.\mathrm{N}_{3}\right)\right]\left(\mathrm{ClO}_{4}\right)$ ), with 4-bromobenzoate (bba) and 2,2'dipyridylamine (dpya) ligands, was successfully synthesized via the stoichiometric reaction of reactants in ethanolic solution. Dark-blue crystals were obtained through solvent evaporation within one week. The crystals of the compound exhibited monoclinic, P21/c and symmetry. The molecular structure of the compound $\mathbf{1}$ is presented in Figure 1. Crystallographic data, bond distances, and angles relevant to the metal coordination sphere of the compound $\mathbf{1}$ are listed in Tables 1-2.

Copper(II) has a disordered square planar geometry and is coordinated with two nitrogen atoms $(\mathrm{Cu}-\mathrm{N}=$ 1.928 (4) and 1.938 (4) ^) from a chelating dpya ligand and two oxygen atoms $(\mathrm{Cu}-\mathrm{O}=1.976(3)$ and 2.017 (3) $\AA$ ) from the carboxylate group of the dpya ligand in $\mu^{2}$ mode. The +2 charge on the copper ion is balanced with a coordinated deprotonated dpya and perchlorate anion as counter ion. The geometry is far removed from the ideal square plane, principally because of the "bite" of dpya (N1-Cu1-N2 = 95.34 (16)degr) and bba (O1$\mathrm{Cu} 1-\mathrm{O} 2=65.19(14)$ degr $)$. Large deviations were 
Table 2. Selected bond lengths $(\AA)$ and angles (degr).

\begin{tabular}{llll}
\hline Bond Lengths & & \multicolumn{2}{c}{ Bond Angles } \\
\hline $\mathrm{Br}(1)-\mathrm{C}(15)$ & $1.895(5)$ & $\mathrm{N}(1)-\mathrm{Cu}(1)-\mathrm{O}(2)$ & $165.29(15)$ \\
$\mathrm{Cu}(1)-\mathrm{N}(1)$ & $1.928(4)$ & $\mathrm{N}(2)-\mathrm{Cu}(1)-\mathrm{O}(2)$ & $98.38(14)$ \\
$\mathrm{Cu}(1)-\mathrm{N}(2)$ & $1.938(4)$ & $\mathrm{N}(1)-\mathrm{Cu}(1)-\mathrm{O}(1)$ & $100.41(15)$ \\
$\mathrm{Cu}(1)-\mathrm{O}(2)$ & $1.976(3)$ & $\mathrm{N}(2)-\mathrm{Cu}(1)-\mathrm{O}(1)$ & $161.48(15)$ \\
$\mathrm{Cu}(1)-\mathrm{O}(1)$ & $2.017(3)$ & $\mathrm{O}(2)-\mathrm{Cu}(1)-\mathrm{O}(1)$ & $65.19(14)$ \\
$\mathrm{C}(10)-\mathrm{N}(2)$ & $1.346(6)$ & $\mathrm{C}(11)-\mathrm{O}(1)-\mathrm{Cu}(1)$ & $87.3(3)$ \\
$\mathrm{N}(3)-\mathrm{C}(6)$ & $1.355(6)$ & $\mathrm{N}(2)-\mathrm{C}(10)-\mathrm{C}(9)$ & $123.4(5)$ \\
$\mathrm{N}(1)-\mathrm{Cu}(1)-\mathrm{N}(2)$ & $5.34(16)$ & $\mathrm{O}(1)-\mathrm{C}(11)-\mathrm{O}(2)$ & $118.4(4)$ \\
& & $\mathrm{C}(11)-\mathrm{O}(2)-\mathrm{Cu}(1)$ & $89.1(3)$ \\
& & $\mathrm{C}(6)-\mathrm{N}(2)-\mathrm{Cu}(1)$ & $124.2(3)$ \\
& & $\mathrm{C}(10)-\mathrm{N}(2)-\mathrm{Cu}(1)$ & $117.3(3)$ \\
& & $\mathrm{C}(5)-\mathrm{N}(1)-\mathrm{Cu}(1)$ & $124.7(3)$ \\
\hline
\end{tabular}

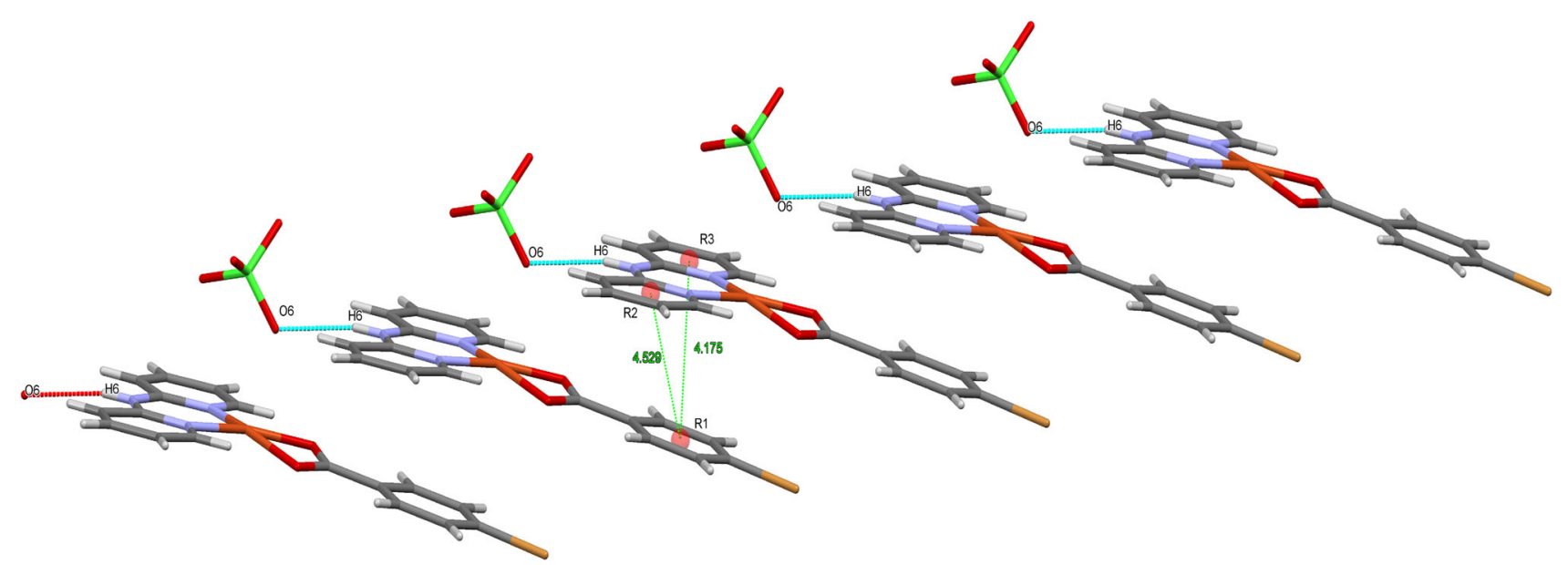

Figure 2. Chain formation of complex via hydrogen bonding and $\pi \cdots \pi$ interactions along $a$ direction.

observed from 180degr for the N1-Cu1-O2 (165.29 (15)degr) and N2-Cu1-O1 angle (161.48 (15)degr). The chelate ring adopts an approximate plane conformation, which the observed torsion angles; C5N3N1C6 and $\mathrm{Cu} 1 \mathrm{O} 2 \mathrm{C} 11 \mathrm{O} 1$ are $-1.0(8) \mathrm{deg} r$ and 1.2(4)degr, respectively.

Weak intermolecular hydrogen bonding interactions are observed between the perchlorate ion and dpya. Two mononuclear units are linked by two N-H $\cdots$ O hydrogen bonds between the nitrogen atom of the coordinated dpya and the oxygen atoms of the lattice perchlorate ion, with an N3 ‥ O6 distance of 2.898 (6) $\AA$ (N3 H6 $\cdots$ O6). In addition, the $\pi \cdots \pi$ interactions between the two parallel rings of the dpya and bba ligands $(\mathrm{R} 1=\mathrm{C} 12 \mathrm{C} 13 \mathrm{C} 14 \mathrm{C} 15 \mathrm{C} 16 \mathrm{C} 17, \mathrm{R} 2=\mathrm{N} 1 \mathrm{C} 1 \mathrm{C} 2 \mathrm{C} 3 \mathrm{C} 4$, and $\mathrm{R} 3=\mathrm{N} 2 \mathrm{C} 6 \mathrm{C} 7 \mathrm{C} 8 \mathrm{C} 9 \mathrm{C} 10), \mathrm{R} 1 \cdots \mathrm{R} 2=4.529 \AA$ and $\mathrm{R} 1 \cdots$ $\mathrm{R} 3=4.175 \AA$, form a chain along $a$ direction (Figure 2).

\subsection{Spectroscopic study}

The X-ray structure of the complex is consistent with the infrared spectra. The band observed between 3042 and
$3094 \mathrm{~cm}^{-1}$ is attributed to the aromatic $\nu(\mathrm{C}-\mathrm{H})$ vibration of two coordinated ligands. Carboxylate group asymmetric and symmetric vibration peaks were observed at 1644 and $1484 \mathrm{~cm}^{-1}$, respectively. The neutral ligand azomethine $\nu(\mathrm{C}=\mathrm{N})$ vibration peak difference between the coordinated and the uncoordinated form is found to be about $60 \mathrm{~cm}^{-1}$, indicating that metal center and nitrogen atom coordination occurs. Two bands encountered at 625 and $769 \mathrm{~cm}^{-1}$ are related to the nitrogen atoms of dipyridylamine and metal center coordination.

The UV-Vis spectrum of the complex shows three absorption bands at 244, 295 and $312 \mathrm{~nm}$ in acetonitrile solution. The lower wavelength band is dedicated to anionic carboxylate group $\pi \rightarrow \pi^{*}$ transitions. The other two absorption bands are related to the $n \rightarrow \pi^{*}$ transitions of dpya ligand. Additionally, $\mathrm{d} \rightarrow \mathrm{d}$ transitions were not observed.

Based on the magnetic measurements of the solid $\mathrm{Cu}$ (II) complex at room temperature, the magnetic moment value is 1.4 B.M., and it is consistent with one unpaired electron system. 
Table 3. Copper complex catalyzed oxidation of primary and secondary alcohols.

\begin{tabular}{|c|c|c|c|c|}
\hline Entry & Substrate & $\begin{array}{l}\text { Products, } \\
\text { Conv. (\%) }\end{array}$ & $\begin{array}{c}\text { Total Conv. }^{\text {b }} \\
(\%)\end{array}$ & $\begin{array}{c}\text { TON/TOF } \\
\left(h^{-1}\right)\end{array}$ \\
\hline 1 & & $\begin{array}{l}14(1 \mathrm{~min}) \\
36(2 \mathrm{~h}) \\
71(6 \mathrm{~h})\end{array}$ & $71(6 h)$ & $71 / 12$ \\
\hline 2 & & $\begin{array}{l}22(1 \mathrm{~min}) \\
17(2 \mathrm{~h}) \\
10(4 \mathrm{~h})\end{array}$ & $\begin{array}{l}35(1 \mathrm{~min}) \\
76(2 \mathrm{~h}) \\
90(6 \mathrm{~h})\end{array}$ & $90 / 15$ (6h) \\
\hline 3 & & $29(6 \mathrm{~h})$ & $100(24 \mathrm{~h})$ & $100 / 4(24 h)$ \\
\hline 4 & & $\begin{array}{c}20(1 \mathrm{~min}) \\
86(6 \mathrm{~h}) \\
100(24 \mathrm{~h})\end{array}$ & $100(24 \mathrm{~h})$ & $100 / 4$ \\
\hline 5 & & $13(6 h)$ & $13(6 \mathrm{~h})$ & $13 / 2$ \\
\hline
\end{tabular}

a Reaction conditions: alcohol $\left(9.3 \times 10^{-4} \mathrm{~mol}\right)$, catalyst $(0.1 \mathrm{~mol} \%), \mathrm{H}_{2} \mathrm{O}_{2}(0.192 \mathrm{mmol})$, water $(10 \mathrm{~mL}), \mathrm{T}=$ $70{ }^{\circ} \mathrm{C}$

${ }^{\mathrm{b}}$ Determined with GC analysis

\subsection{Catalytic experiments}

The catalytic oxidation reactions of primary/secondary alcohol and alkene were performed in a $50 \mathrm{~mL}$ roundbottom flask with a temperature-controlled magnetic stirrer at $70{ }^{\circ} \mathrm{C}$. The experiments were carried out in water and $\mathrm{H}_{2} \mathrm{O}_{2}$ or TBHP as the oxygen source. Comparison of catalytic results was presented in Tables 3-4 and Figures 3-4. A blank experiment showed that the uncatalyzed oxidation of the studied alcohols and alkenes were negligible under the applied conditions.

The results indicated that a synthesized compound 1 has a catalytic effect on both the studied alcohol and alkene oxidations in water. The activity of the $\mathrm{Cu}$ (II) $/ \mathrm{H}_{2} \mathrm{O}_{2} / \mathrm{H}_{2} \mathrm{O}$ catalytic system is found to be higher in aromatic alcohols than in aliphatic ones. In a $6 \mathrm{~h}$ reaction time, the total \% conversions of 90 , 
Table 4. Copper complex catalyzed oxidation of alkenes.

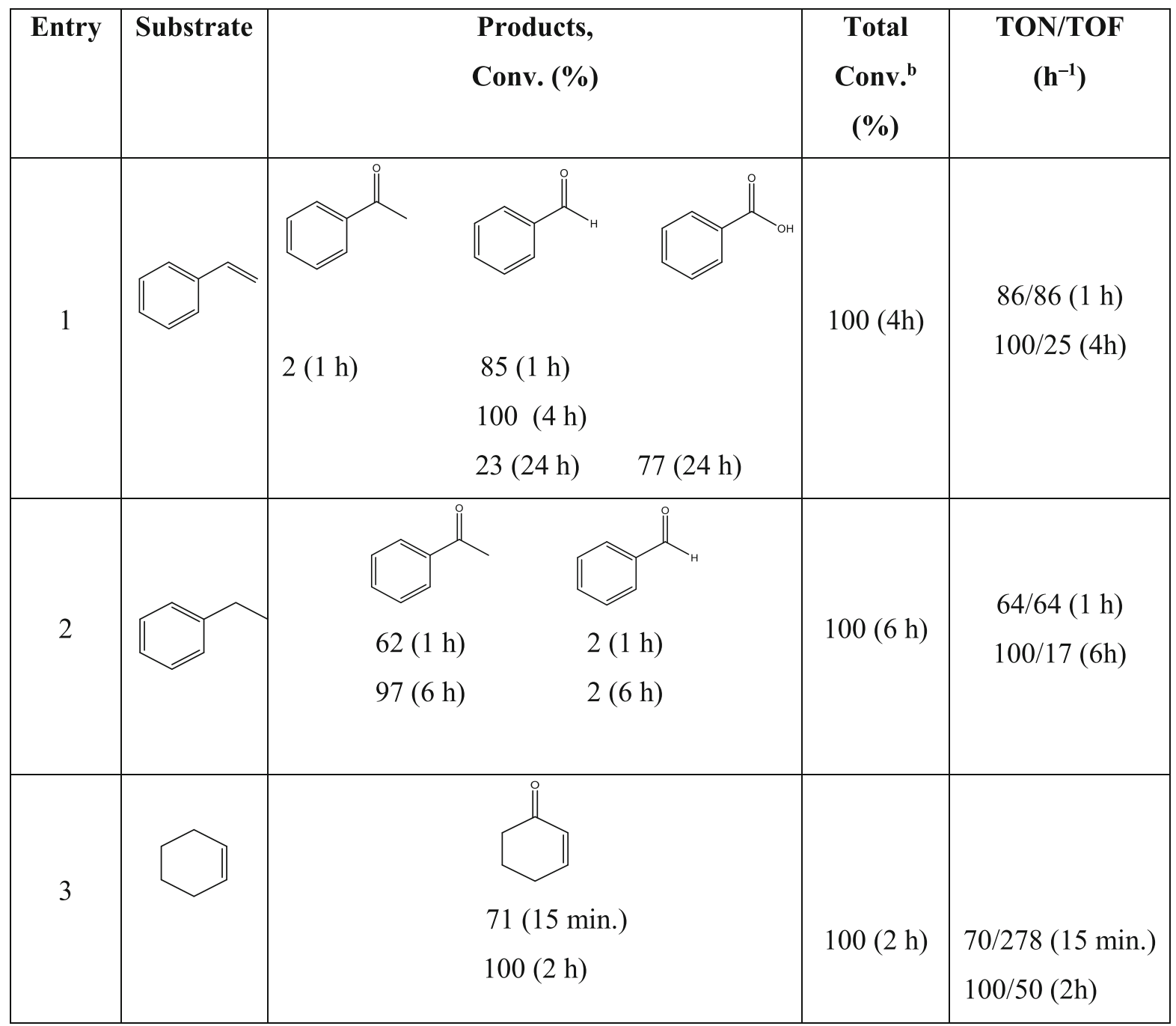

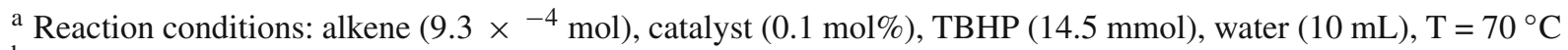

${ }^{\mathrm{b}}$ Determined with GC analysis

$86,71,29$, and 13 were obtained for cinnamyl alcohol, 1-phenylethanol, benzyl alcohol, cyclohexanol, and 1-heptanol, respectively. Benzaldehyde was detected as a major product of both benzyl alcohol and cinnamyl alcohol oxidations (Table 3, Entries-2, 4, 1, 3, 5).

In benzyl alcohol oxidation, the substrate selectively converted to one product, benzaldehyde, with $71 \%$ formation in $6 \mathrm{~h}$ reaction time (Entry 1). Additionally, formation of the over oxidation product, benzoic acid, was not observed even when the reaction was prolonged to $24 \mathrm{~h}$. In the oxidation of secondary alcohol phenyl ethanol, a TOF value of 1200 was reached at the first minute of the catalytic oxidation with $20 \%$ acetophenone formation. After a $6 \mathrm{~h}$ reaction time, acetophenone was the only product observed at $86 \%$ (Entry 4). The highest TOF value was obtained in allylic-type alcohol, cinnamyl alcohol oxidation $\left(2100 \mathrm{~h}^{-1}\right.$ at the first minute of the reaction with $35 \%$ total conversion). After a 4 h reaction time, conversion increased to $84 \%$, and the aldehyde selectivity was found to be $88 \%$ as benzaldehyde (Entry 2). Cinnamaldehyde is a minor product with a selectivity value of $12 \%$ after $4 \mathrm{~h}$. The result that needs to be emphasized is cinnamaldehyde carboxylation, which is converted to benzaldehyde through the carboxylation process as the reaction proceeds. As a cyclic alcohol, cyclohexanol was poorly oxidized to the corresponding ketone, and 29\% cyclohexanone formation was obtained at $6 \mathrm{~h}$ reaction time (Entry 3 ). The lowest conversion rate was observed in 1-heptanol oxidation as the primary aliphatic alcohol (13\% total conversion, Table 3, Entry 5). Generally, aliphatic alcohols are less reactive than aromatic alcohols, and these findings are in agreement with published results. ${ }^{42,43}$

In alkene oxidation reactions, hydrogen peroxide has been found to be an ineffective oxygen source. That is why TBHP was used as oxidant. The $\mathrm{Cu}(\mathrm{II}) / \mathrm{TBHP} / \mathrm{H}_{2} \mathrm{O}$ 


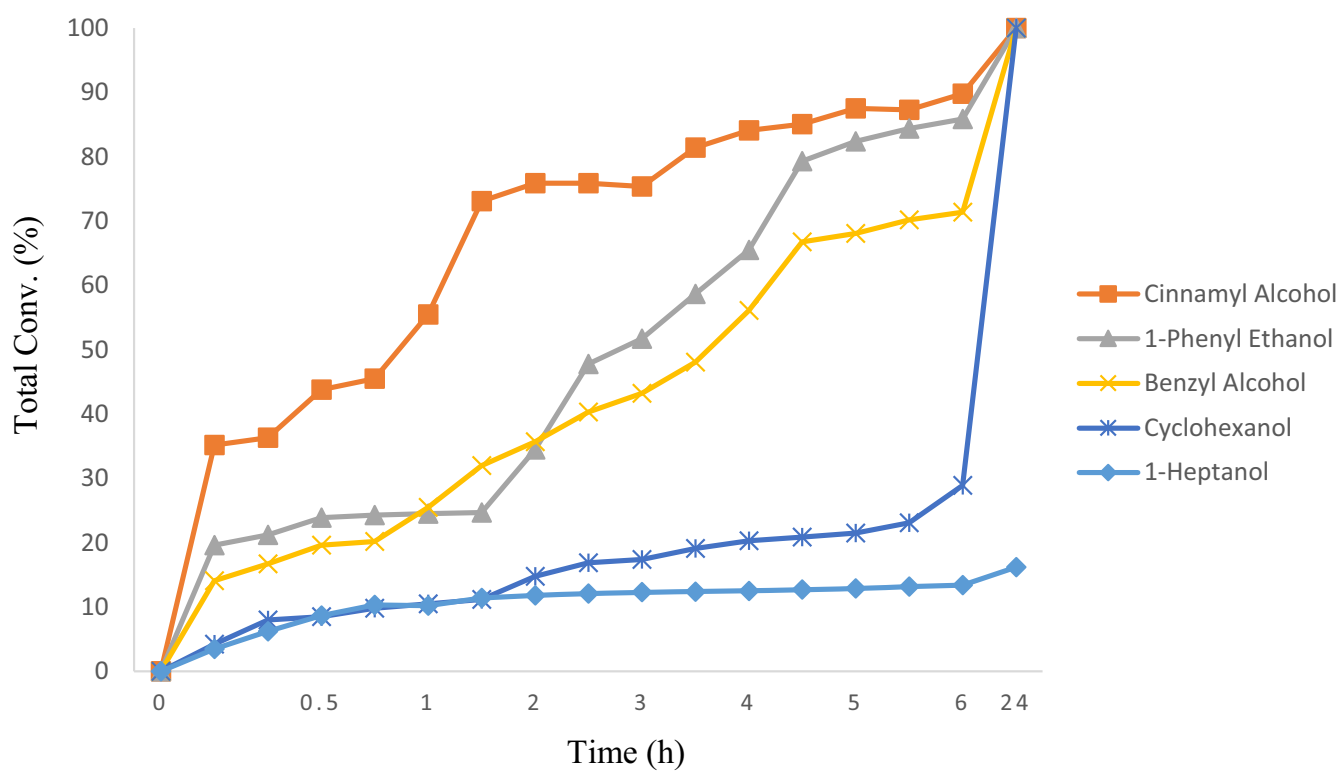

Figure 3. Comparison of alcohol oxidation with compound in water.

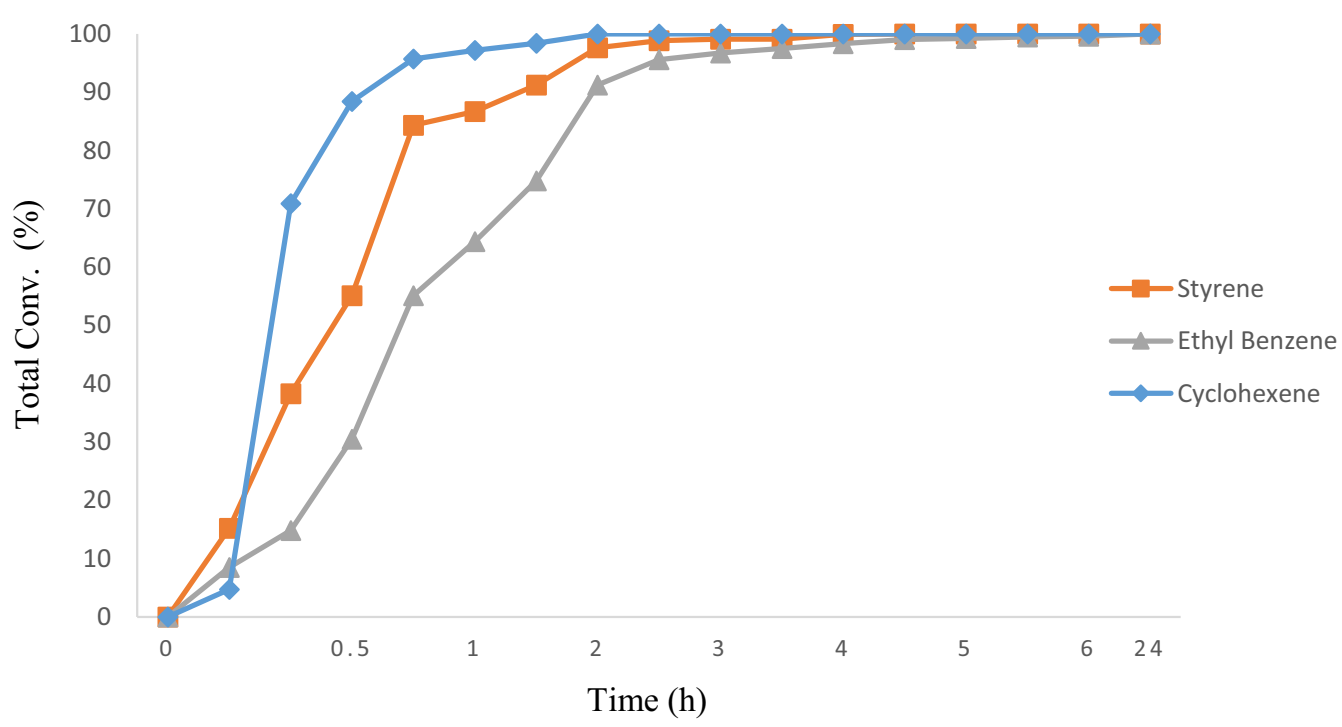

Figure 4. Comparison of alkene oxidation with compound in water.

catalytic system shows good activities of styrene, ethylbenzene, and cyclohexene oxidation with reasonably good selectivity (Table 4 ) at $70{ }^{\circ} \mathrm{C}$. In styrene oxidation, acetophenone $(2 \%)$ and benzaldehyde $(85 \%$, selectivity $98 \%$ ) were observed in the initial period of reaction with a TON value of 87 . After $4 \mathrm{~h}$ of reaction time, complete conversion of styrene to benzaldehyde was observed as the sole product. When the reaction continued, the over-oxidation product, benzoic acid, was obtained (77\% after $24 \mathrm{~h}$ ) (Entry 1). In ethylbenzene oxidation, acetophenone was obtained as a major product and changed from $62 \%$ (TOF $=64.4)$ to $97 \%$ (TOF $=$ $17 \mathrm{~h}^{-1}$.) within a $1-6 \mathrm{~h}$ reaction time (overall selectivity
97\%) (Entry 2). Among the studied alkenes, cyclohexene oxidation is the fastest catalytic reaction (in the first $15 \mathrm{~min}$ of the reaction time, $71 \%$ yield and $\mathrm{TOF}=$ $280 \mathrm{~h}^{-1}$ ). In cyclohexene, the oxidation of the carboncarbon double bond does not convert to cyclohexene oxide (epoxide) with TBHP, whereas the oxidation of the allylic $\mathrm{C}-\mathrm{H}$ bond results in 2-cyclohexene-1-ol, which is further oxidized to 2-cyclohexene-1-one as one product within a reaction time of $2 \mathrm{~h}\left(\mathrm{TOF}=50 \mathrm{~h}^{-1}\right)$ (Table 2, Entry 3).

The adopted $\mathrm{Cu}(\mathrm{II}) / \mathrm{TBHP}\left(\right.$ or $\left.\mathrm{H}_{2} \mathrm{O}_{2}\right) / \mathrm{H}_{2} \mathrm{O}$ system was simpler, greener, and more efficient for alcohol and especially alkene oxidation under mild reaction condi- 
tions. A clean oxidant $\mathrm{H}_{2} \mathrm{O}_{2}$ was used since it produces water, and more importantly, using water as a solvent is an important feature of a green chemical reaction.

It should be emphasized that such level of yields is extremely good in the field of alkene (particularly cyclohexene) oxidation, especially for the inertness of the saturated hydrocarbon and mild reaction conditions. ${ }^{44,45}$ The obtained products and yields are also comparable with or even superior to those achieved using other related copper catalysts bearing carboxylate and $\mathrm{N}$ based ligands. ${ }^{32-36}$

\section{Conclusions}

We have developed a new water-soluble copper(II)complex (1) as a catalyst precursor bearing 4-bromobenzoate and neutral 2,2'-dipyridylamine ligands. The compound has been fully characterized using $\mathrm{X}$-ray and other spectroscopic techniques. It is found that compound is an active catalyst for the peroxidative oxidation of alkenes and alcohols with $\mathrm{H}_{2} \mathrm{O}_{2}$ and/or TBHP under mild conditions without any promoter in water, a green solvent system. In particular, high conversions for alkene oxidation, and an excellent selectivity for 2-cyclohexe-1-one for cyclohexene oxidation in water were obtained. Using a low-cost catalyst, $\mathrm{TBHP} / \mathrm{H}_{2} \mathrm{O}_{2}$, and water as solvent made our catalytic system attractive and environmentally sustainable.

\section{Supplementary Information (SI)}

All spectroscopic measurement data (FT-IR, UV-Vis and Single crystal $\mathrm{x}$-ray structure) are given in supplementary file. CCDC 1578707 contains the supplementary crystallographic data for the compound $\mathbf{1}$. These data can be obtained free of charge via http://www.ccdc.cam.ac.uk/conts/retrieving.html, or from the Cambridge Crystallographic Data Centre, 12 Union Road, Cambridge CB2 1EZ, UK; fax: (+44) 1223336-033; or e-mail: deposit@ccdc.cam.ac.uk. Supplementary Information is available at www.ias.ac.in/chemsci

\section{Acknowledgements}

Authors thankfully acknowledge the Medical Plants and Medicine Research Centre of Anadolu University, Eskişehir, Turkey for using X-ray Diffractometer.

\section{References}

1. Jessop P G 1999 Homogenous catalysis in supercritical fluids Chem. Rev. 99475

2. Wassercheid P and Keim W 2000 Ionic Liquids-New "Solutions" for Transition Metal Catalysis Angew Chem. Int. Edit. 393772
3. Wolf E and Koten G 1999 Florous phase separation techniques in catalysis Chem. Soc. Rev. 2837

4. Azemi T F, Kondaveti L and Bisht K S 2002 Solventless Enantioelective Ring-Opening Polymerization of Substituted $\varepsilon$-Caprolactones by Enzymatic Catalysis Macromolecules 353380

5. Ramin M, Jutz F Grunwaldt J D and Baiker A 2005 Solventless synthesis of propylene carbonate catalysed by chromium-salen complexes: Bridging homogeneous and heterogeneous catalysis J. Mol. Catal. A $\mathbf{2 4 2}$ 24232

6. Suzuka T, Sueyoshi H and Ogihara K 2017 Recyclable Polymer-Supported Terpyridine-Palladium Complex for the Tandem Aminocarbonylation of Aryl Iodides to Primary Amides in Water Using $\mathrm{NaN}_{3}$ as Ammonia Equivalent Catalysts 7107

7. Sindhu K S, Ujwaldev S M, Krishana K K and Anilkumar G 2017 A green approach for arylation of phenols using iron catalysis in water under aerobic conditions J. Catal. 348146

8. Sharma S K and Jashra R V 2015 Aqueous phase catalytic hydroformylation reactions of alkenes Catal. Today 24770

9. Shabbir S, Lee $\mathrm{S}$, Lim M, Lee H, Ko H, Lee $\mathrm{Y}$ and Rhee H 2017 Pd nanoparticles on reverse phase silica gel as recyclable catalyst for Suzuki-Miyaura cross coupling reaction and hydrogenation in water J. Organomet. Chem. 846296

10. Anna M M D, Mali M, Mastrolilli P, Cotugno P and Monopoli A 2014 Oxidation of benzyl alcohols to aldehydes and ketones under air in water using a polymer supported palladium catalyst J. Mol. Catal. A $\mathbf{3 8 6}$ 114

11. Ng Y H, Ikeda S, Harada T, Morita Y and Matsumura M 2008 An efficient and reusable carbon-supported platinum catalyst for aerobic oxidation of alcohols in water Chem. Commun. 3181

12. Aliende C, Manrique M P, Jalon F A, Manzano B R, Rodriguez A M and Espino G 2012 Arene Ruthenium Complexes as Versatile Catalysts in Water in both Transfer Hydrogenation of Ketones and Oxidation of Alcohols. Selective Deuterium Labeling of rac-1Phenylethanol Organometallics 316106

13. Wu J, Liu Y, Ma X, Liu P, Gu C and Dai B 2016 Highly selective copper-catalyzed oxidation of benzyl alcohols to aromatic aldehydes in water at room temperature Appl. Organomet. Chem. 30577

14. Monfared $\mathrm{H} \mathrm{H}$, Nather $\mathrm{C}$, Winkler $\mathrm{H}$ and Janiak C 2012 Highly selective and "green" alcohol oxidations in water using aqueous $10 \% \mathrm{H}_{2} \mathrm{O}_{2}$ and ironbenzenetricarboxylate metal-organic gel Inorg. Chim. Acta 39175

15. Chen G, Chen L, Ma L, Kwong H K and Lau T C 2016 Photocatalytic oxidation of alkenes and alcohols in water by a manganese(V) nitrido complex Chem. Commun. 52 9271

16. Figiel P J, Sibaouih A, Ahmad J U, Nieger M, Raisanen M T, Leskela M and Repo T 2009 Aerobic Oxidation of Benzylic Alcohols in Water by 2,2,6,6Tetramethylpiperidine-1-oxyl (TEMPO)/Copper(II) 2N-Arylpyrrolecarbaldimino Complexes Adv. Synth. Catal. 3512625 
17. Kopylovich M N, Mahmudov K T, Haukka M, Figiel P J, Mizar A, da Silva A L and Pombeiro A J L 2011 WaterSoluble Cobalt(II) and Copper(II) Complexes of 3-(5Chloro-2-hydroxy- 3-sulfophenylhydrazo)pentane-2,4dione as Building Blocks for 3D Supramolecular Networks and Catalysts for TEMPO-Mediated Aerobic Oxidation of Benzylic Alcohols Eur. J. Inorg. Chem. 4175

18. Zhang G F, Han X W, Luan Y X, Wang Y, Wen X, Xu L, Ding C G and Gao J R 2013 Copper-catalyzed aerobic alcohol oxidation under air in neat water by using a watersoluble ligand $R S C A d v .319255$

19. Xie J B, Bao J J, Li H X, Tan D W, Li H Y and Lang J P 2014 An efficient approach to the ammoxidation of alcohols to nitriles and the aerobic oxidation of alcohols to aldehydes in water using $\mathrm{Cu}(\mathrm{II}) /$ pypzacac complexes as catalysts $R S C A d v .454007$

20. Bullock R M 2007 Ein Eisenkatalysator zur Hydrierung von Ketonen unter milden Bedingungen Angew. Chem. 1197504

21. Gamez P, Arends I W C E and Sheldon R A 2004 Room Temperature Aerobic Copper-Catalysed Selective Oxidation of Primary Alcohols to Aldehydes Adv. Synth. Catal. 346805

22. Uber J S, Vogels Y, Van den Helder D, Mutikainen I, Turpeinen U, Fu W T, Roubeau O, Gamez P and Reedijk J 2007 Pyrazole-Based Ligands for the [CopperTEMPO]-Mediated Oxidation of Benzyl Alcohol to Benzaldehyde and Structures of the $\mathrm{Cu}$ Coordination Compounds Eur. J. Inorg. Chem. 264197

23. Meder M B and Gade L H 2004 Coordination Chemistry of 1,3-Bis(2-pyridylimino)- and 1,3-Bis- (2thiazolylimino)isoindole Copper Complexes: Investigation of Their Catalytic Behavior in Oxidation Reactions Eur. J. Inorg. Chem. 2716

24. Murphy E F, Mallat T and Baiker A 2000 Allylic oxofunctionalization of cyclic olefins with homogeneous and heterogeneous catalysts Catal. Today $\mathbf{5 7} 115$

25. Jiang D, Mallat T, Meier D M, Urakawa A and Baiker A 2010 Copper metal-organic framework: Structure and activity in the allylic oxidation of cyclohexene with molecular oxygen J. Catal. 27026

26. Dutta B, Bera R and Koner S 2007 Anchoring of Copper Complex in MCM-41 Matrix: A Highly Efficient Catalyst for Epoxidation of Olefins by tert-BuOOH Langmuir 232492

27. Dutta B, Jana S, Bera R, Saha P K and Koner S 2007 Immobilization of copper Schiff base complexes in zeolite matrix: Preparation, characterization and catalytic study Appl. Catal. A $\mathbf{3 1 8} 89$

28. Mukherjee S, Samanta S, Roy B C and Bhaumik A 2006 Efficient allylic oxidation of cyclohexene catalyzed by immobilized Schiff base complex using peroxides as oxidants Appl. Catal. A $\mathbf{3 0 1} 79$

29. Mizar A, Fátima M, Silva C G, Kopylovich M N, Mukherjee S, Mahmudov K T and Pombeiro A J L 2012 Water-Soluble Copper(II) Complexes with a SulfonicFunctionalized Arylhydrazone of $\beta$-Diketone and Their Application in Peroxidative Allylic Oxidation of Cyclohexene Eur. J. Inorg. Chem. 2305
30. $\mathrm{Hu} \mathrm{Z}$ and Kerton F M 2012 Room temperature aerobic oxidation of alcohols using $\mathrm{CuBr} 2$ with TEMPO and a tetradentate polymer based pyridyl-imine ligand Appl. Catal. A $\mathbf{4 1 3} 332$

31. Ünver $\mathrm{H}$ and Kani I 2017 Homogeneous oxidation of alcohols in water catalyzed with $\mathrm{Cu}$ (II)- triphenyl acetate/bipyridyl complex Polyhedron 134257

32. Kirillova M V, Paiva P T, Carvalho W A, Mandelli D and Kirillov A M 2017 Mixed-ligand aminoalcoholdicarboxylate copper(II) coordination polymers as catalysts for the oxidative functionalization of cyclic alkanes and alkenes Pure Appl. Chem. 8961

33. Shul'pin G B 2016 New Trends in Oxidative Functionalization of Carbon-Hydrogen Bonds: A Review Catalysts 650

34. Kirillov A M, Kirillova M V and Pombeiro A J L 2012 Multicopper complexes and coordination polymers for mild oxidative functionalization of alkanes Coord. Chem. Rev. 2562741

35. Dias S P, Kirillova M V, André V, Kłak J and Kirillov A M 2015 New tricopper(II) cores self-assembled from aminoalcohol biobuffers and homophthalic acid: synthesis, structural and topological features, magnetic properties and mild catalytic oxidation of cyclic and linear C5-C8 alkanes Inorg. Chem. Front. 525

36. Fernandes T A, André V, Kirillov A M and Kirillova M V 2017 Mild homogeneous oxidation and hydrocarboxylation of cycloalkanes catalyzed by novel dicopper(II) aminoalcohol-driven cores J. Mol. Catal. A Chem. 426 357

37. SMART, Bruker AXS 2000

38. Sheldrick G M 2008 A Short history of SHELX Acta Crystallogr. Sect. A 64112

39. Sheldrick G M 1997 SHELXS-97, Program for crystal structure solution. University of Gottingen

40. Macrae C F, Edgington P R, McCabe P, Pidcock E, Shields G P, Taylor R, Towler M and Streek J 2006 Mercury: visualization and analysis of crystal structures $J$. Appl. Crystallogr. 39453

41. Spek AL PLATON - A Multipurpose Crystallographic Tool Utrecht Utrecht University The Netherlands 2005

42. Samantha S, Das S, Samantha P K, Dutta S and Biswas P 2013 A mononuclear copper(II) complex immobilized in mesoporous silica: an efficient heterogeneous catalyst for the aerobic oxidation of benzylic alcohols $R S C A d v$. 319455

43. Conejo M M, Avila P, Alvarez E and Galindo A 2017 Synthesis and structure of nickel and copper complexes containing the $\mathrm{N}$-allyl-o-hydroxyacetophenoniminato ligand and the application of copper complex as catalyst for aerobic alcohol oxidations Inorg. Chim. Acta $\mathbf{4 5 5}$ 638

44. Banu A P, Sugisaki C, Gharsa T, Marty J D, Gascon I, Krimer M, Pozzi G, Desbat B, Quici S, Lattes I R and Mingotaud C 2005 monolayers of salen derivatives as catalytic planes for alkene oxidation in water Chem. Eur. J. 116032

45. Basle O and Li C J 2007 Copper catalyzed oxidative alkylation of $\mathrm{sp}^{3} \mathrm{C}-\mathrm{H}$ bond adjacent to a nitrogen atom using molecular oxygen in water Green Chem. 91047 